\title{
EGFR controls bone development by negatively regulating mTOR- signaling during osteoblast differentiation
}

\author{
Markus Linder ${ }^{1}$ Manfred Hecking ${ }^{1,6}$ - Elisabeth Glitzner ${ }^{1}$ - Karin Zwerina ${ }^{2}$ - Martin Holcmann ${ }^{1}$ Latifa Bakiri ${ }^{4}$. \\ Maria Grazia Ruocco ${ }^{3} \cdot$ Jan Tuckermann ${ }^{5} \cdot$ Georg Schett $^{2} \cdot$ Erwin F. Wagner $^{4} \cdot$ Maria Sibilia $^{1}$
}

Received: 3 August 2017 / Revised: 27 November 2017 / Accepted: 28 November 2017

(c) The Author(s) 2018. This article is published with open access

\begin{abstract}
Mice deficient in epidermal growth factor receptor $\left(E g f r^{-l-}\right.$ mice $)$ are growth retarded and exhibit severe bone defects that are poorly understood. Here we show that EGFR-deficient mice are osteopenic and display impaired endochondral and intramembranous ossification resulting in irregular mineralization of their bones. This phenotype is recapitulated in mice lacking EGFR exclusively in osteoblasts, but not in mice lacking EGFR in osteoclasts indicating that osteoblasts are responsible for the bone phenotype. Experiments are presented demonstrating that signaling via EGFR stimulates osteoblast proliferation and inhibits their differentiation by suppression of the IGF-1R/mTOR-pathway via ERK1/2-dependent upregulation of IGFBP-3. Osteoblasts from $\mathrm{Egfr}^{-1-}$ mice show increased levels of IGF-1R and hyperactivation of mTORpathway proteins, including enhanced phosphorylation of 4E-BP1 and S6. The same changes are also seen in Egfr ${ }^{-l-}$ bones. Importantly, pharmacological inhibition of mTOR with rapamycin decreases osteoblasts differentiation as well as rescues the low bone mass phenotype of $\mathrm{Egfr}^{-l-}$ fetuses. Our results demonstrate that suppression of the IGF-1R/mTOR-pathway by EGFR/ERK/IGFBP-3 signaling is necessary for balanced osteoblast maturation providing a mechanism for the skeletal phenotype observed in EGFR-deficient mice.
\end{abstract}

Markus Linder and Manfred Hecking contributed equally to this work.

Edited by E Gottlieb

Electronic supplementary material The online version of this article (https://doi.org/10.1038/s41418-017-0054-7) contains supplementary material, which is available to authorized users.

Maria Sibilia

Sibilia-Office@meduniwien.ac.at

1 Department of Internal Medicine I, Institute of Cancer Research, Comprehensive Cancer Center, Medical University of Vienna, Vienna, Austria

2 Department of Internal Medicine 3, Friedrich-AlexanderUniversity Erlangen-Nürnberg (FAU), Universitätsklinikum Erlangen, Erlangen, Germany

3 Department of Internal Medicine III, Medical University of Vienna, Vienna, Austria

4 Spanish National Cancer Research Center (CNIO), Madrid, Spain

5 Institute of Comparative Molecular Endocrinology, University of Ulm, Ulm, Germany

6 Present address: Department of Internal Medicine III, Medical University of Vienna, Waehringer Guertel 18-20, Vienna A-1090, Austria

\section{Introduction}

Skeletal development requires complex and coordinated interplay between mesenchymal cells-chondrocytes and osteoblasts-at various stages of differentiation. The succession of events whereby osteoblast formation follows chondrocyte differentiation resulting in bone formation in long bones of vertebras is termed "endochondral ossification" [1]. Differentiation of osteoblasts is induced by upregulation of specific transcription factors accompanied by the expression of factors that facilitate mineralized extracellular matrix formation [2].

Genetic ablation of the epidermal growth factor receptor (EGFR) in mice revealed its intricate role during embryonic and postnatal development [3, 4]. Mice lacking the EGFR $\left(E g f^{--}\right)$have major organ defects and die either in utero or shortly after birth, depending on the genetic background [35]. Among other developmental abnormalities EGFRdeficient mice are severely growth retarded and exhibit skeletal defects [6]. We have previously reported that long bones of EGFR-deficient mice display a greatly increased zone of hypertrophic chondrocytes, suggesting that EGFR negatively regulates condrocyte maturation [6]. Similar 
Fig. 1 Egfr ${ }^{-l-}$ mice are osteopenic. a Alcian blue and Alizarin red whole body mount showing skeletal mineralization of $E g f r^{\mathrm{wt}}$ and $E g f r^{-/-}$mice on postnatal day 7 (P7). b Skeletal preparations of WT and $\mathrm{KO}$ mice: femur and spine. $\mathbf{c} \mu \mathrm{CT}$ image of 7-day-old $E g f r^{\mathrm{wt}}$ (left) and $E g f r^{-/-}$(right) mice d Von Kossa staining of $E g f r^{\mathrm{wt}}$ and Egfr ${ }^{-1-}$ calvaria at P7; scales: $100 \mu \mathrm{m}$ for lower and $20 \mu \mathrm{m}$ for higher magnification. e Von Kossa staining showing calcification of $E g f r^{\mathrm{wt}}$ and $E g f r$ ${ }^{-I-}$ tibiae on P7; scales: $500 \mu \mathrm{m}$ for lower and and $100 \mu \mathrm{m}$ for higher magnification. $\mathbf{f}$ Histomorphometric analysis of $E g f r^{\mathrm{wt}}$ and $E g f r^{-l-}$ tibiae from P1 to P14: Quantification of bone volume/tissue volume (BV/TV), trabecular number (Tb.N), trabecular separation (Tb.Sp), trabecular thickness (Tb.Th) and osteoblast number per bone perimeter $(\mathrm{N} . \mathrm{Ob} / \mathrm{B}$. Pm). P1: $n=6$. P7: $n=5$. P14: $n=6 \mathrm{WT}, 3 \mathrm{KO}$ mice
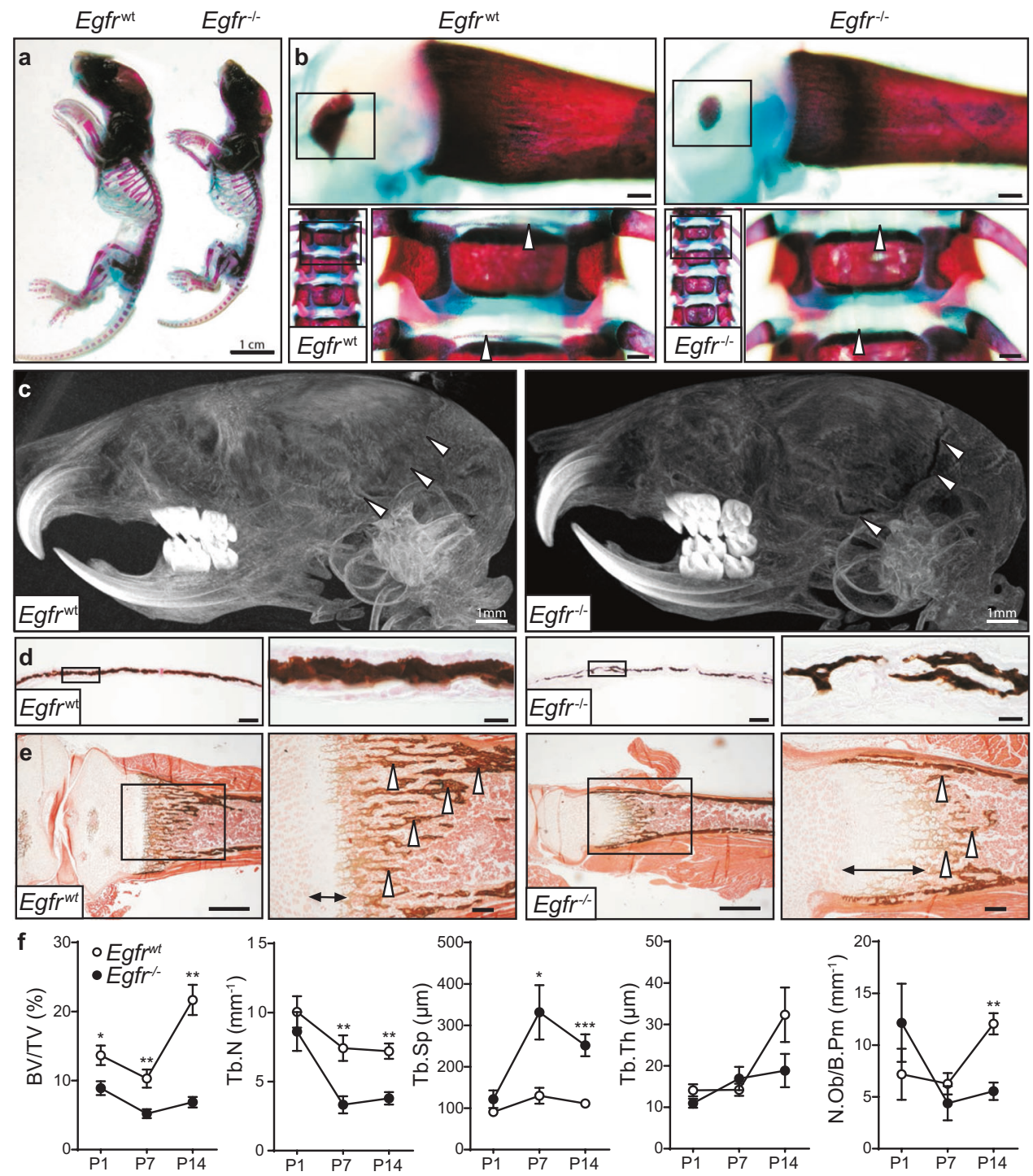

observations were made by Wang et al. [7], who in addition found delayed primary ossification with irregular distribution of osteoblasts in $\mathrm{Egfr}^{-/-}$embryos [7].

Moreover, EGFR knock-in mice where the murine EGFR is replaced by the human counterpart display low EGFR activity in the bone and show impaired endochondral ossification and an increased hypertrophic chondrocyte zone [6]. Similarly, mice with reduced EGFR activity by combined expression of a dominant-negative Egfr Wa5 allele and deletion of an Egfrfloxed allele using Collal-Cre mice (Collal-Cre Egfr $r^{\mathrm{wa} 5 / f}$ ), display bone abnormalities starting around 3 months of age [8]. Mice lacking the membrane-anchored metalloproteinase ADAM17, responsible for cleavage of several membrane-bound cytokines and growth factors including EGFR ligands also develop expanded zones of hypertrophic chondrocytes, and chondrocyte-specific deletion of ADAM17 results in shortened long-bones with increased cartilage mineralization [9].

EGF treatment of WT calvariae increased the proliferation of osteoprogenitor cells and maintained them in an undifferentiated state [10]. Accordingly, $\mathrm{Egfr}^{-1-}$ osteoblasts show reduced proliferation but elevated differentiation indicating that EGFR is essential during osteoblast maturation [8]. However, the underlying molecular mechanisms has so far not been investigated. It is also unclear whether the bone defects observed in adult mice result from developmental defects or arise later during bone remodeling. The mouse models employed so far have not allowed to investigate this effect, since incomplete EGFR deletion was observed using Col-Cre mice and osteoblastindependent effects of the ubiquitously expressed, dominant-negative $\mathrm{Wa} 5$ on other ErbB family members cannot be excluded [8]. 
Fig. 2 EGFR deletion leads to reduced proliferation and pERK1/2 in bone-lining cells. Representative images and quantifications of IHC stainings on femur sections from 7-dayold $E g f r^{\mathrm{wt}}$ and $E g f r^{-1-}$ mice against (a) p-Histone $\mathrm{H} 3(n=$ 5), (b) PCNA $(n=5)$, and (c) pERK1/2 $(n=3)$. Scales: 200 $\mu \mathrm{m}$ (lower magnification) and $20 \mu \mathrm{m}$ (higher magnification)

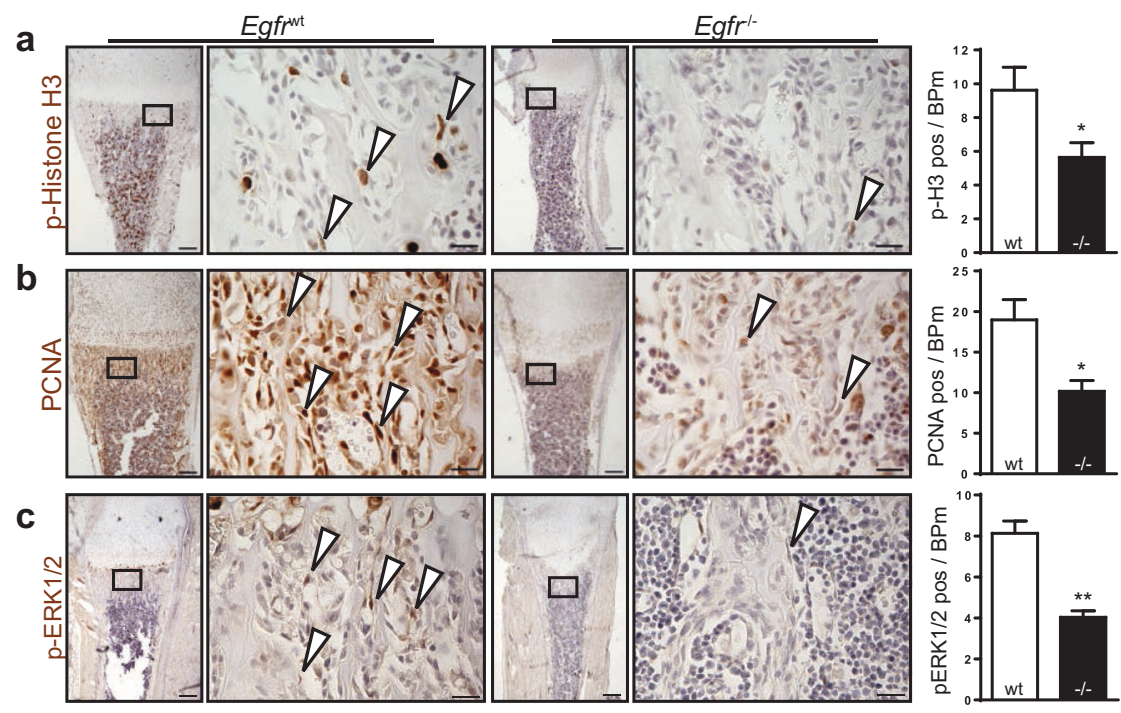

Here we investigated the bone phenotype occurring in the first weeks of age in $E g f r^{-1-}$ mice and in adult mice in which $E g f r$ is conditionally deleted in the osteoblast lineage using Egfr flf Runx2-Cre $\left(E g f r^{\Delta \mathrm{Ob}}\right)$ mice. We found that EGFR signaling in osteoblasts negatively regulates IGF-1R/ mTOR pathway via ERK1/2 dependent up-regulaion of IGFBP-3 to coordinate differentiation during embryonic and postnatal bone formation.

\section{RESULTS}

\section{$\mathrm{Egfr}^{-1-}$ mice show impaired endochondral and intramembranous ossification}

We first performed an analysis of the skeleton of $E g f r^{-l-}$ mice that survived until postnatal day 7 (P7). Bones of Egfr ${ }^{-l-}$ mice were less mineralized and reduced in length compared to WT littermates (Fig. 1a). Whole-mount body staining revealed reduced centers of secondary ossification in long bones and irregular calcification of vertebral endplates in EGFR-deficient mice (Fig. 1b). Additionally, Egfr ${ }^{-1-}$ mice showed reduced mineralization of costal cartilage (Fig. S1a).

While most bones develop by endochondral ossification, the lateral clavicles and parts of the skull are formed by intramembranous ossification, where mesenchymal cells directly differentiate into osteoblasts without chondrocyte involvement $[1,11]$. To determine whether the bone phenotype of $\mathrm{Egfr}^{-/-}$mice can occur independently of the cartilage defects, we examined skulls of $\mathrm{Egfr}^{-1-}$ mice. $\mathrm{\mu CT}$ analysis revealed an impaired cranial suture closure on day 14 (Fig. 1c), indicating that EGFR also plays an important role during intramembranous ossification. Furthermore, while straight, well-organized columns of calcified extracellular matrix (ECM) with a clearly delineated border were observed in WTs, these structures were lacking in $E g \mathrm{fr}^{-1-}$ calvariae (Fig. 1d). Taken together our results show that $E g f r$ deletion leads to impaired bone development in newborn mice with defects in both endochondral and intramembranous ossification.

$E g \mathrm{fr}^{-1-}$ long-bones displayed a low-bone-mass phenotype with less calcified bone and fewer bony trabeculae on P7 (arrowheads; Fig. 1e) and a thickened growth plate (arrows; Fig. 1e). Egfr ${ }^{-l-}$ tibiae exhibited thicker zones of ECM located at the cortical sides reaching into the center of the bone (Fig. S1b) indicating that the mineralization process in $\mathrm{Egfr}^{-1-}$ bones was impaired due to misbalanced deposition of ECM by osteoblasts.

Histomorphometric analyses confirmed that the ratio of bone volume over tissue volume (BV/TV) was significantly lower in $\mathrm{Egfr}^{-1-}$ mice (Fig. 1f). The trabecular number (Tb. $\mathrm{N})$ was decreased while trabecular separation (Tb.Sp) was increased at P7 and P14, although trabecular thickness (Tb. Th) was not significantly changed (Fig. 1f). While Egfr ${ }^{-1}$ mice were born with osteoblast numbers (N.Ob) comparable to WT levels, their amount was significantly decreased on P14 (Fig. 1f).

\section{EGFR is essential for osteoblast proliferation and ERK1/2 activation}

As osteoblasts are essential for bone mineralization we next focused on the role of EGFR during osteoblastogenesis. We found decreased proliferation of primary pre-osteoblasts lacking the EGFR [6] (Fig. S2a), without any significant differences in the number of apoptotic cells (Fig. S2b). Additionally, Egfr ${ }^{-l-}$ osteo-progenitors showed reduced BrdU and Cyclin D1 levels, indicating that EGFR deletion 
Fig. $3 E g f r^{\Delta \mathrm{Ob}}$ mice phenocopy the bone phenotype of $E g f r^{-l-}$ mice. a H\&E stainings showing distal femurs with increased zone of hypertrophic chondrocytes in 6-day-old $E g f r^{\Delta \mathrm{Ob}}$ mice; scales: $200 \mu \mathrm{m}$ (lower magnification) and 100 $\mu \mathrm{m}$ (higher magnification). b $\mu \mathrm{CT}$ image of femurs from 3months old $E g f r^{\mathrm{wt}}$ and $E g f r^{\Delta \mathrm{Ob}}$ littermate; scale: $1 \mathrm{~mm}$. c Quantification of femur length of $E g f r^{\mathrm{wt}}$ and $E g f r^{\Delta \mathrm{Ob}}$ mice with indicated age
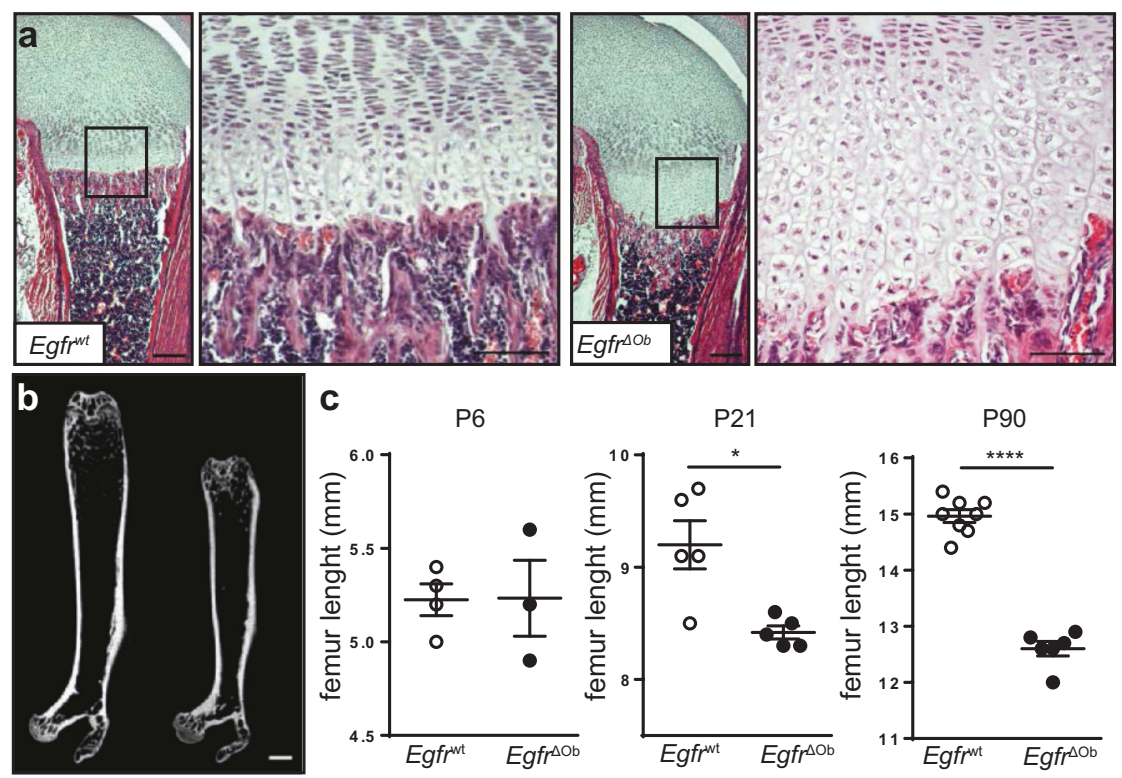

leads to cell autonomous proliferation defects without affecting apoptosis (Figs. S2c, d).

To confirm that the observed defects are also occurring in vivo, we evaluated the proliferation of bone-lining cells in femoral sections of $E g f r^{-l-}$ and $E g f r^{\mathrm{wt}}$ mice. The number of cells positive for the mitosis marker p-Histone $\mathrm{H} 3$ (Fig. 2a) and the S-phase related marker PCNA (Fig. 2b) were significantly reduced in $\mathrm{Egfr}^{-1-}$ mice indicating that EGFR is crucial for proliferation during bone development.

The ERK pathway, a major EGFR downstream signaling pathway, plays a central role in cell proliferation [12]. Therefore, we analyzed the phosphorylation of ERK1/2 in bone lining cells at P7. Egfr ${ }^{-1-}$ mice exhibited significantly reduced numbers of $\mathrm{p}$-ERK1/2 positive cells on their trabecular bone (Fig. 2c), suggesting that the proliferation defects during bone development are based on impaired ERK1/2 activation.

\section{Osteoblast-specific deletion of EGFR leads to bone defects}

To address whether the bone phenotype in $E g f r^{-1-}$ mice is due to cell-autonomous defects in osteoblasts, $E g f r^{\mathrm{f} / \mathrm{f}}$ mice were crossed to an osteoblast-specific Cre line (Runx2-Cre), to generate Egfr flf Runx2-Cre $\left(E g f r^{\Delta \mathrm{Ob}}\right)$ mice [13]. Complete deletion of EGFR was confirmed by Western Blot in cultured osteoblasts and by IHC in long bones (Figs. S3a, b). As shown by qRT-PCR from RNA isolated from bone and cartilage of $E g f r^{\mathrm{wt}}$ and $E g f r^{\Delta \mathrm{Ob}}$ femurs, deletion of Egfr was restricted to bone tissue, but not cartilage (Fig. S3c). Egfr ${ }^{\Delta \mathrm{Ob}}$ mice developed normally without any significant differences in overall body length (Fig. S3d). On P6 the zone of hypertrophic chondrocytes of Egfr ${ }^{\Delta \mathrm{Ob}}$ mice was significantly increased, comparable to $\mathrm{Egfr}^{-/-}$ mice (Fig. 3a). Importantly, Egfr ${ }^{\Delta \mathrm{Ob}}$ mice showed reduced length of long bones which was significant by P21 and became more severe with age (Figs. 3b, c). These results demonstrate that EGFR signaling in osteoblasts is essential for proper bone development.

\section{Adult Egfr ${ }^{\mathrm{AOb}}$ mice develop a low-bone-mass phenotype}

The augmented zone of hypertrophic chondrocytes was accompanied by increased expression of the hypertrophic chondrocyte marker CollOal in long bones of Egfr ${ }^{\Delta \mathrm{Ob}}$ mice on P21 (Fig. 4a). Significantly elevated Runt-related transcription factor-2 (Runx2) mRNA levels together with reduced Colagen1a1 (Collal) mRNA and reduced Osteocalcin (Ocn) mRNA and protein levels (Figs. 4a, S4a) indicate that EGFR deletion in osteoblasts leads to impaired mineralization due to premature differentiation of osteoprogenitors. Histomorphological analysis revealed a progressive, low-bone-mass phenotype with decreased bone volume and trabecular number in adult $E g f r^{\Delta \mathrm{Ob}}$ mice (Figs. 4b, c). Additional trabecular bone markers further showed reduced trabecular thickness and increased spacing in $E g f r^{\Delta \mathrm{Ob}}$ mice (Fig. S4b). Less osteoblasts on the trabecular bone and reduced osteocalcin serum levels (Fig. 4d) indicate that the low-bone-mass is based on osteoblast defects.

To exclude that EGFR in osteoblasts indirectly affects osteoclastogenesis, osteoclast-specific markers were analyzed in long bones and serum. No significant differences in osteoclast number could be detected neither in young nor in adult $E g f r^{\Delta \mathrm{Ob}}$ mice. Furthermore, $E g f r^{\Delta \mathrm{Ob}}$ mice did not 
Fig. $4 E g f r^{\Delta \mathrm{Ob}}$ mice show severe bone defects. a qRT-PCR analysis: RNA isolated from whole femurs of 21-day-old $E g f r^{\mathrm{wt}}$ and $E g f r^{\Delta \mathrm{Ob}}$ mice; $n=7$ WT, $9 \Delta \mathrm{Ob}$. b H\&E stainings showing distal femurs of 3months-old $E g f r^{\mathrm{wt}}$ and $E g f r^{\Delta \mathrm{Ob}}$ mice; scales: $200 \mu \mathrm{m}$. c

Histomorphometric analysis of $\mathrm{WT} / \Delta \mathrm{Ob}$ long-bones at P6, P21 P90 and P210: Quantification of bone volume/tissue volume (BV/TV) and trabecular number (Tb.N). P6: $n=4$ WT, $3 \Delta \mathrm{Ob}$. P21: $n=5$. P90: $n=8 \mathrm{WT}, 6$ $\Delta$ Ob. P210: $n=4 \mathrm{WT}, 6 \Delta \mathrm{Ob}$ mice. d Osteoblast number (N. $\mathrm{Ob} / \mathrm{B} . \mathrm{Pm})$ and surface on the trabecular bone (Ob.S/BS) at $\mathrm{P} 21(n=7 \mathrm{WT}, 10 \Delta \mathrm{Ob})$ and $\mathrm{P} 210(n=6 \mathrm{WT}, 8 \Delta \mathrm{Ob})$ and Osteocalcin as measured by ELISA in Serum at P21 $(n=4$ $\mathrm{WT}, 6 \Delta \mathrm{Ob})$ and $\mathrm{P} 210(n=5$ WT, $9 \Delta \mathrm{Ob}$ )
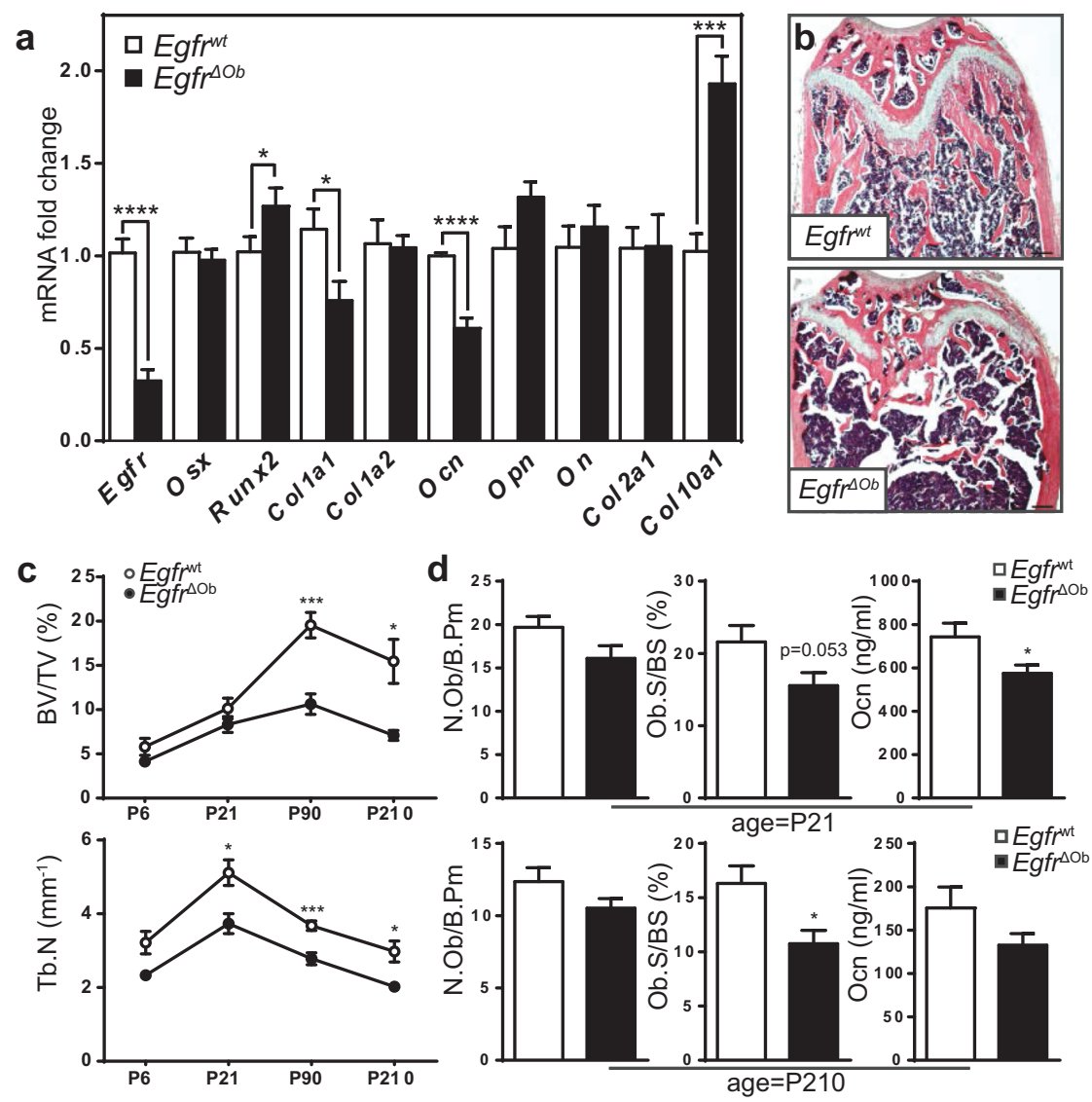

show any differences of the serum biomarker for bone resorption C-terminal telopeptide (CTX-1) (Fig. S4c).

Additionally, we assessed whether EGFR directly affects osteoclast development by breeding Egfr fff mice to LysMCre mice that express Cre recombinase in the myeloid lineage $\left(E g f r^{\Delta \mathrm{Oc}}\right)$. Osteoclasts isolated from $E g f r^{\Delta \mathrm{Oc}}$ mice showed reduced EGFR protein levels (Fig. S4d), but did not display any bone defects nor differences in the number of osteoclasts in trabecular bones or serum CTX-1 (Fig. S4e). Bone-marrow derived pre-osteoclasts from $E g f r^{-l-}$ mice did not show any significant differences in their ability to form osteoclasts in vitro (Fig. S4f). Finally, OC number in trabecular bones and serum CTX-1 levels were not altered in $E g \mathrm{fr}^{-/-}$mice (Fig. S4g) indicating that lack of EGFR does not affect osteoclastogenesis.

\section{Enhanced differentiation of $\mathrm{Egfr}^{-/-}$osteoblasts correlates with IGF-1R/mTOR activation}

Once confirmed that the defects are primarily in the osteoblast lineage, we employed primary osteoblasts from $E g f r^{\mathrm{wt}}$ and $E g f r^{--}$mice to investigate the underlying molecular mechanism. As osteoblasts from $E_{g f r^{-I}}$ mice display enhanced differentiation [6] and the IGF-1R pathway was shown to play a central role during osteoblast differentiation
[14], we investigated whether EGFR regulates bone development by interacting with the IGF-1R signaling pathway. We detected elevated levels of total and phosphorylated IGF1R $\beta$ in differentiated osteoblasts isolated from $E g \mathrm{fr}^{-1-}$ mice (Fig. 5a). Furthermore, $\mathrm{Egfr}^{-1-}$ osteoblasts showed increased total and phosphorylated protein levels of the IGF-1R adapter protein insulin receptor substrate 1 (IRS-1) and its downstream target mTOR (Fig. 5a). Importantly, IGF-1R/IRS1/mTOR up-regulation was ligand independent as the levels of IGF-1 and IGF-2 were not altered (Fig. S5a).

To investigate the kinetics of mTOR activation we next analyzed multiple time points during osteoblast differentiation. IGF-1R/mTOR-pathway proteins were consistently present at higher levels and were hyperphosphorylated during differentiation in $\mathrm{Egfr}^{-1-}$ osteoblasts indicating that IGF-1R/mTOR-signaling remained elevated throughout the whole culture period (Fig. 5b).

IHC staining on femur sections of WT and EGFRdeficient mice at $\mathrm{P} 7$ revealed that the mTOR-signaling pathway was also altered in vivo. In line with the in vitro findings, significantly increased phosphorylation of mTOR and its main downstream targets 4E-BP1 and S6 protein were observed in $\mathrm{Egfr}^{-1-}$ long-bones (Figs. 5c, d). Additionally, $E g f r^{\Delta \mathrm{Ob}}$ mice also showed reduced p-S6 protein 
Fig. 5 Enhanced differentiation correlates with mTOR-signaling. a Western blot analysis of $E g f r^{\mathrm{wt}}$ and $E g \mathrm{fr}^{-1-}$ osteoblasts under differentiation conditions; isolated on differentiation day 14. b Western blot analyses of $E g f r^{\mathrm{wt}}$ and $E g f r^{-l-}$ osteoblasts under differentiation conditions on days $6,9,12$, and 15 . c Immunohistochemical staining of p-mTOR, p-4E-BP1 and p-S6 on trabecular bone sections from distal femurs of P7 $E g f r^{\mathrm{wt}}$ and $\mathrm{Egfr}^{-/-}$littermates; scales: 200 $\mu \mathrm{m}$ (lower magnification) and $20 \mu \mathrm{m}$ (higher magnification). d Quantification of IHC staining, shown as positive cells per bone perimeter (B.Pm); $n \geq 3$ a

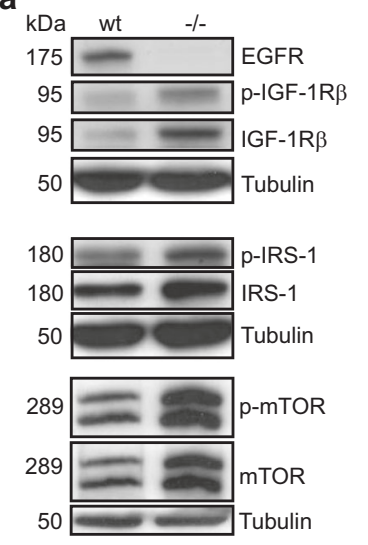

b

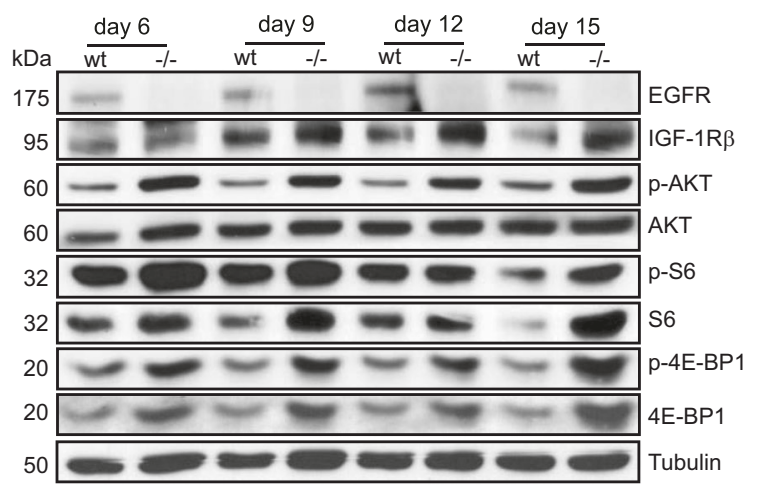

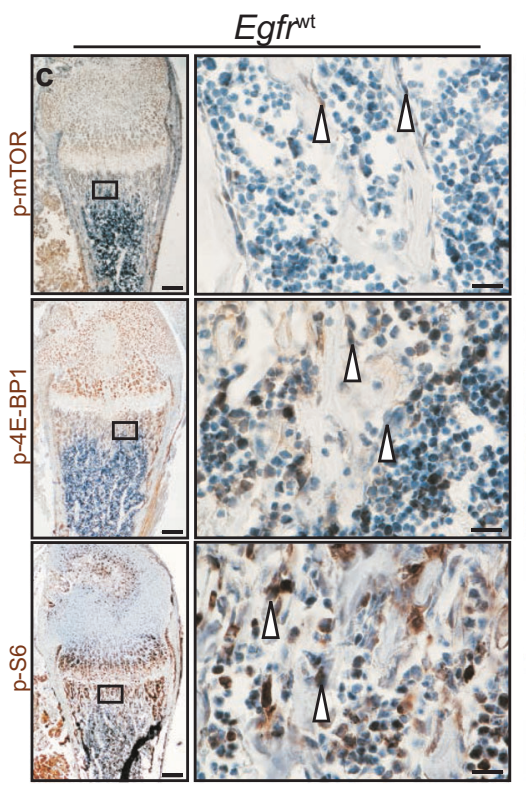
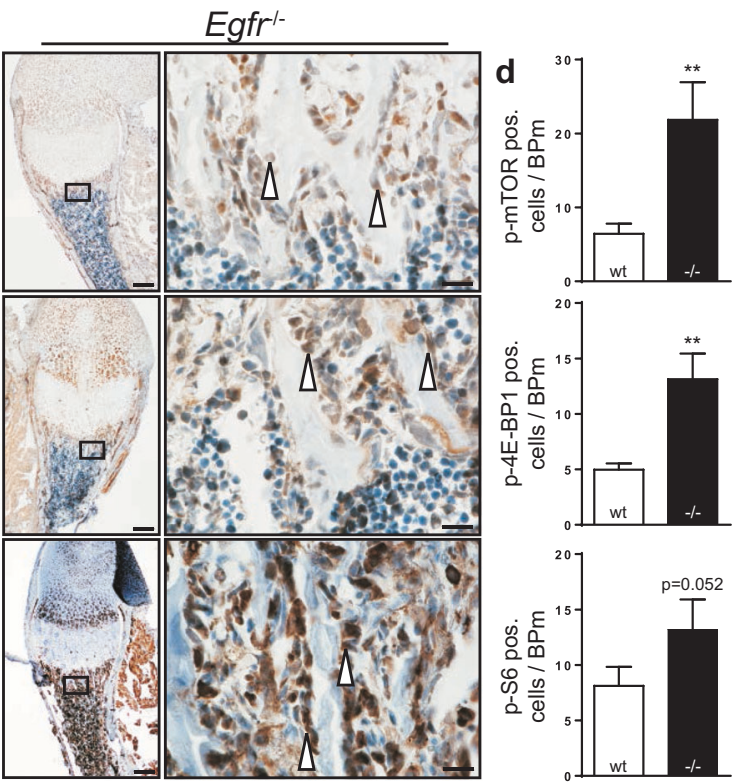

levels in bone-lining cells indicating that this activation depends on osteoblastic EGFR signaling (Figs. S5b, c).

\section{Interplay between EGFR- and IGF-1R-pathways in osteoblast differentiation}

To analyze the cross-talk between EGFR and IGF-1Rsignaling during osteoblast differentiation, WT osteoblasts were cultured under differentiation-inducing conditions together with IGF-1, EGF and/or the ERK1/2 inhibitor U0126. At day 21 bone nodule formation was assessed as a functional read-out for differentiation. Mineralization was enhanced by IGF-1 treatment (Figs. 6a, b) and completely abolished by EGF (Fig. 6c). Addition of EGF was able to suppress IGF-1 induced differentiation in a dose-dependent manner with complete inhibition at $100 \mathrm{ng} / \mathrm{ml}$ (Figs. 6d-f). IGF-1 induced differentiation was further increased when ERK1/2 signaling was blocked by U0126 (Figs. 6g, h). ERK inhibition together with EGF and IGF-1 stimulation rescued the EGF-induced hypo-differentiation phenotype resulting in normalized bone nodule formation comparable to untreated controls (Fig. 6i). Taken together our results show that IGF$1 \mathrm{R}$ signaling enhances, whereas EGFR signaling inhibits osteoblast differentiation and that EGFR signaling dominates by negatively regulating IGF-1R via ERK1/2.

To dissect the underlying molecular mechanism we analyzed the activation of EGFR and IGF-1R downstream proteins in differentiated WT osteoblasts cultured for 21 days in the presence of EGF / IGF-1 and U0126. EGF treatment prevented phosphorylation of IGF-1R $\beta$ with reduced activation of the mTOR/S6/4E-BP1 pathway, whereas IGF-1 induced the phosphorylation of IGF-1R $\beta$ / mTOR/S6/4E-BP1 (Fig. 6j). When osteoblasts were cultured with both growth factors, activation was again reduced suggesting that EGFR signaling is able to block differentiation via IGF-1R $\beta$ inhibition. Importantly, EGFinduced downregulation of the IGF-1R $\beta$ pathway was partly restored when ERK1/2 was blocked, indicating that EGFR 


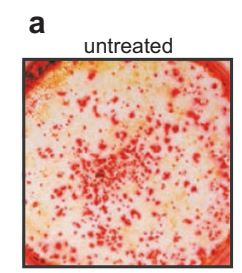

b

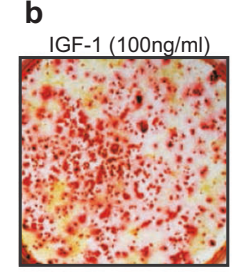

c

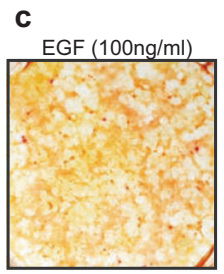

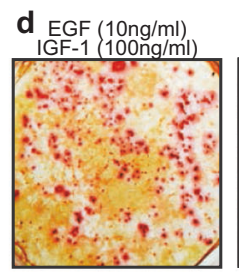

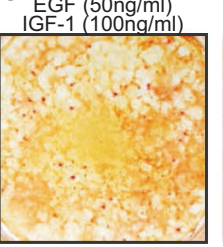

$f_{E G F(100 \mathrm{ng} / \mathrm{ml})}$
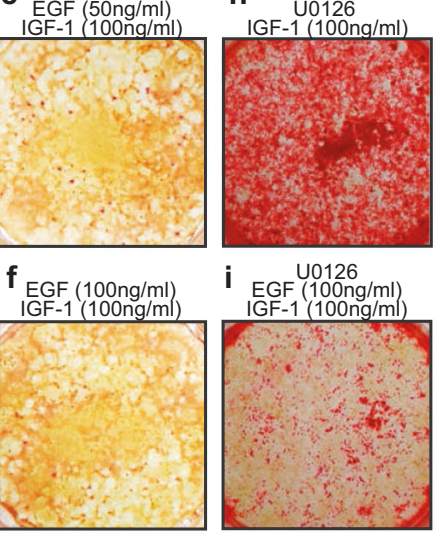

U0126 EGF $(100 \mathrm{ng} / \mathrm{ml})$ $e_{\text {EGF }(50 \mathrm{ng} / \mathrm{ml})}$

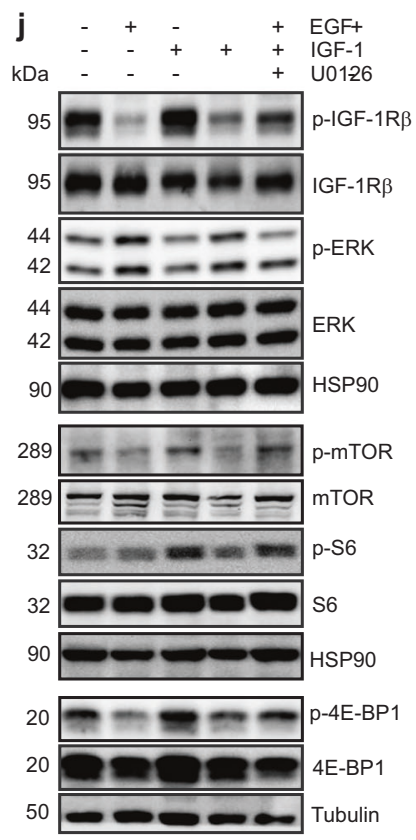
2
2
5
0
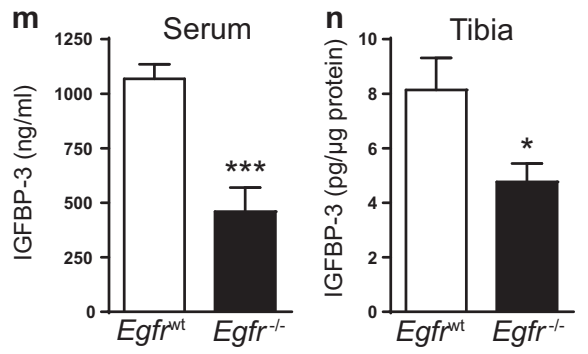

0

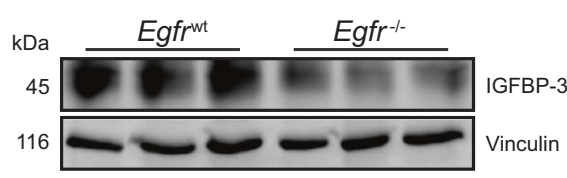

Fig. 6 Differentiation in WT osteoblasts is mediated by specific components of the IGF-1R-pathway and inhibited by EGF. a-i Alizarin red staining of WT osteoblasts after 21 days (D21) in culture under differentiation conditions ( + AA, $\beta$ GP) with EGF, IGF-1, and/or U0126 over the whole culture period. Pictures taken from a 6-well plate. $\mathbf{j}, \mathbf{k}$ Western blot analysis of differentiated WT osteoblasts (D21) cultured with EGF (100 ng), IGF-1 (100 ng) and/or U0126 (10 $\mu \mathrm{M})$. $\mathbf{I}$ Western Blot analysis of undifferentiated osteoblast precursor cells

negatively regulates differentiation by down-regulating IGF-1R $\beta /$ mTOR signaling via ERK1/2 (Fig. 6j). No differences in insulin receptor $\beta$ (IR $\beta$ ) phosphorylation could be detected indicating that EGF stimulation exclusively downregulates IGF-1R without affecting IR $\beta$ activation (Fig. S6a).

To prove that reduced activation of IGF- $1 \mathrm{R} \beta$ is a direct consequence of EGF stimulation, we cultured WT osteoblasts under differentiation conditions for 21 days, starved them for $24 \mathrm{~h}$ and stimulated for $10 \mathrm{~min}$ with EGF or IGF-1. As expected, EGF treatment induced a strong activation of p

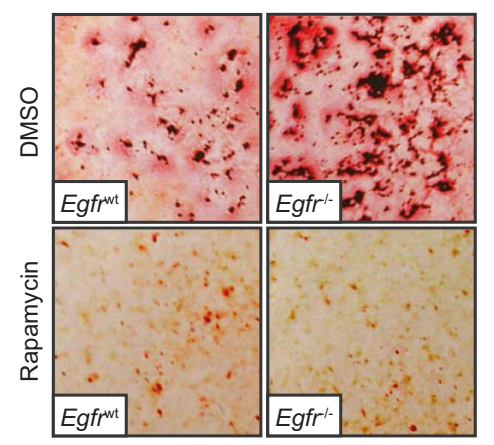

cultured in $\alpha \mathrm{MEM}+10 \% \mathrm{FCS}$ after $4 \mathrm{~h}$ treatment with indicated concentrations of Afatinib. m IGFBP-3 protein levels in serum $(n=7)$ and $\mathbf{n}$ whole tibia lysates $(n=4)$ of 7-day old $E g f r^{\text {wt }}$ and $E g f r^{-l-}$ littermates. o Western Blot analysis of whole tibia protein lysates isolated from 7-day old $E g f r^{\mathrm{wt}}$ and $E g f r^{-/-}$littermates. p Alizarin red staining of differentiated WT and $E g f_{r}{ }^{-1-}$ osteoblasts (D21) cultured with vehicle (DMSO) or Rapamycin $(10 \mathrm{nM})$. Stained with alizarin red

ERK1/2 and at the same time reduced the phosphorylation of IGF-1R $\beta$ whereas IGF-1 stimulation did not affect ERK1/2 signaling (Fig. S6b).

To investigate the mechanism how EGFR signaling suppresses IGF-1R/mTOR signaling we next analyzed IGFBP-3 levels, as IGFBP-3 is known to modulate and repress IGF-1R signaling $[15,16]$. Moreover, it has been shown that EGFR directly regulates IGFBP-3 in primary esophageal cells [17]. We found elevated IGFBP-3 levels in osteoblasts cultured together with EGF or with EGF and IGF-1 whereas IGF-1 alone had no effect (Fig. 6k). 
a

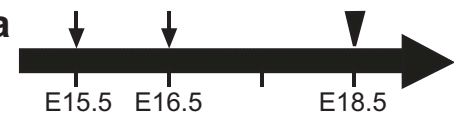

$\downarrow$ Rapamycin $-5 \mathrm{mg} / \mathrm{kg}$ bw, 2x/d

$\nabla$ Analyze embryonic bones

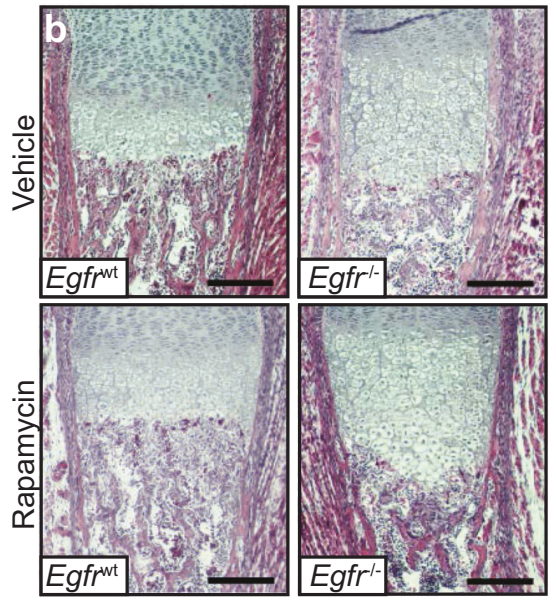

Fig. 7 mTOR inhibition partially rescues bone phenotype of $E g f r^{-l-}$ mice. a Timeline showing experiment outline for in utero Rapamycin treatment. Pregnant mice were subcutaneously injected with $5 \mathrm{mg}$ Rapamycin per $\mathrm{kg}$ bodyweight or Injection-vehicle twice a day on E15.5 and E16.5 b H\&E staining of trabecular bone sections showing distal femurs of $E g f r^{\mathrm{wt}}$ and $E g f r^{-1-}$ embryos on E18.5 after Rapamycin/vehicle treatment; scale: $200 \mu \mathrm{m}$. c Quantification of bone

Importantly, IGFBP-3 up-regulation was a direct consequence of ERK1/2 signaling, as additional treatment with the ERK1/2 inhibitor U0126 normalized EGF-induced IGFBP-3 levels (Fig. 6k). In contrast, EGFR inhibition with Afatinib led to a dose-dependent decrease in IGFBP-3 protein levels along with increased p-mTOR phosphorylation in osteoblast precursors (Fig. 61). In addition, IGFBP-3 was also strongly reduced in the supernatant of osteoblast precursor cells after $48 \mathrm{~h}$ treatment with EGFR inhibitor as compared to DMSO treated controls (Fig. S6c).

In line with our in vitro results, we also found significantly reduced IGFBP-3 in the serum of $E g f r^{-1-}$ and $E g \mathrm{fr}^{\Delta \mathrm{Ob}}$ mice (Figs. 6m, S6d) indicating that EGFR signaling in osteoblasts is essential for IGFBP-3 production. IGFBP-3 levels were also reduced in whole tibia protein lysates of $\mathrm{Egfr}^{-1-}$ mice, as revealed by both ELISA and western blot analysis (Figs. 6n, o). These results demonstrate that EGFR is required for IGFBP-3 production and suppression of IGF-1R/mTOR activation thus providing a mechanistic link between EGFR and IGF-1R signaling and osteoblast differentiation.

To further show that the hyper-differentiation phenotype of $\mathrm{Egfr}^{-1-}$ osteoblasts is indeed a consequence of elevated mTOR activation we next inhibited mTOR in differentiating osteoblasts using rapamycin. Bone nodule
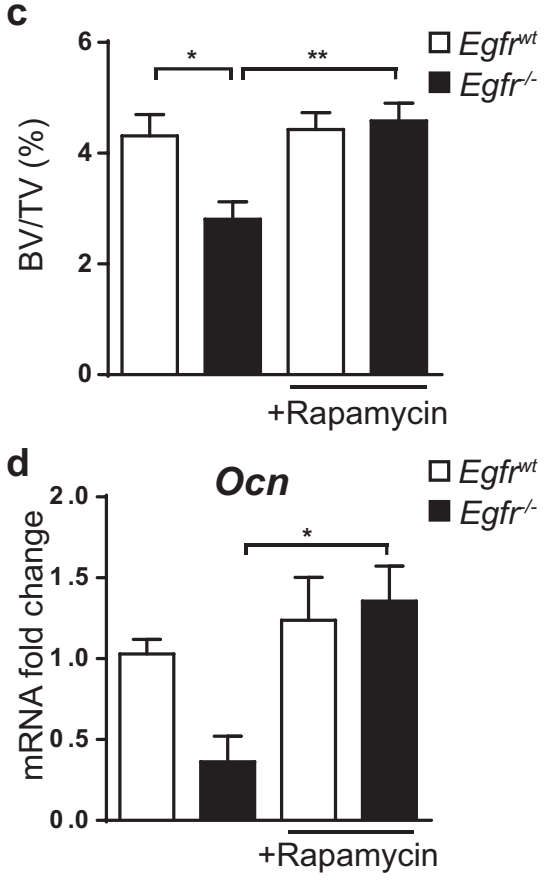

volume relative to total volume (BV/TV) after rapamycin/vehicle treatment; $n=7 \mathrm{WT}, 6 \mathrm{KO}$ mice for vehicle and $6 \mathrm{WT}, 8 \mathrm{KO}$ mice for rapamycin treatment; 5 mothers per treatment group. d mRNA expression levels of Osteocalcin (Ocn) in femurs of E18.5 mice measured by qRT-PCR; $n=9 \mathrm{WT}, 5 \mathrm{KO}$ mice for vehicle and $7 \mathrm{WT}$, $5 \mathrm{KO}$ mice for rapamycin treatment

formation was strongly reduced in the presence of rapamycin (Fig. 6p). Upon rapamycin treatment, phosphorylation of the mTOR downstream proteins 4E-BP1 and S6 was down-regulated in $\mathrm{Egfr}^{-1-}$ cultures similarly to WT osteoblasts (Fig. S6e) demonstrating that the increased differentiation in $E g f r^{-l-}$ osteoblasts can be prevented by mTOR-inhibition.

Taken together our data provide evidence that EGFR controls osteoblasts differentiation via ERK-dependent IGFBP-3 up-regulation, which ensures proper osteoblast maturation by controlling IGF-1R/mTOR signaling.

\section{mTOR inhibition partially rescues bone phenotype of $\mathrm{Egfr}^{-1-}$ embryos}

We next analyzed whether mTOR inhibition during embryonic development, when mineralization starts, can normalize the bone defects in EGFR-deficient mice. Pharmacological inhibition of mTOR during gestation has previously been reported not to cause any bone-specific side effects in mice [18]. We injected pregnant females from EGFR heterozygous intercrosses with rapamycin or vehicle twice a day on E15.5 and on E16.5 and analyzed embryonic bones at E18.5 (Fig. 7a). Rapamycin treatment was not teratogenic nor did it affect litter size or viability of pups 
(Fig. S7a). Inhibition of mTOR signaling pathway was confirmed by p-S6 IHC staining on femurs of fetuses obtained from rapamycin or vehicle-treated mothers (Fig. S7b).

We could not observe any effect on hypertrophic chondrocyte zone in embryonic $E g f r^{-1-}$ bones after rapamycin treatment (Fig. S7c), which is in line with our hypothesis that the hypertrophic chondrocyte phenotype is not responsible for the impaired bone development. However, chemical inhibition of mTOR increased the zone of hypertrophic chondrocytes in WT animals (Fig. S7c) without affecting Egfr expression levels in long-bones (Fig. S7d).

Importantly, after rapamycin treatment bones of $E g f r^{-/-}$ embryos showed BV/TV comparable to WT mice (Figs. 7b, c). Furthermore, Osteocalcin mRNA levels in femurs of $E g f r^{-/-}$embryos from rapamycin-injected mothers were also normalized (Fig. 7d). In addition, rapamycin treatment also normalized the ratio between Runx2 and Osteocalcin mRNA expression in bones of $E g f r^{-/}$embryos (Figs. S7e, f) providing evidence that EGFR signaling suppresses mTOR during bone formation to prevent early maturation of osteoprogenitor cells to ensure the development of functional osteoblasts.

\section{Discussion}

In the present study, we show that EGFR-deficient mice suffer from a complex bone phenotype with decreased bone mass, which starts before birth and persists to adulthood. Moreover, deleting EGFR specifically in the osteoblast or osteoclast lineage demonstrates that EGFR in the osteoblast lineage is essential for adequate bone development.

Histological analyses revealed an enlarged zone of hypertrophic chondrocytes, which could be the reason for the subsequent bone defects. However, we show that both endochondral as well as intramembranous ossification is defective in the absence of EGFR. Since intramembranous ossification does not involve chondrocyte differentiation and cartilage formation, our results suggest that the osteoblast and bone defects are unlikely to result from chondrocyte defects. Therefore, EGFR signaling seems to be required cell-autonomously in osteoblasts. Long-bones of mice with osteoblast-specific deletion of EGFR showed elevated Runx2 with reduced Colagenlal and Osteocalcin expression levels revealing an important role of EGFR during mineralization. This finding also reflects results from published in vitro experiments suggesting that a major function of the EGFR is to maintain a pool of osteoprogenitor cells by downregulating Runx 2 and Osterix in order to prevent premature differentiation [19]. Despite the fact that $E g f r^{-/}$osteoblasts showed elevated mineralization in vitro, both $E g f r^{-1-}$ and $E g f r^{\Delta \mathrm{Ob}}$ mice are osteopenic. This apparent discrepancy might be due to the fact that osteoprogenitor cells lacking the EGFR, which display proliferation defects, cannot form sufficient numbers of osteoblasts to guarantee proper maturation and ossification in vivo.

We identified the mTOR-pathway as a positive regulator of osteoblast differentiation that is suppressed by EGFR signaling. In the absence of EGFR, IGF-1R/mTOR signaling is up-regulated due to reduced IGFBP-3 signaling leading to accelerated osteoblast differentiation thus not allowing a sufficient number of osteoprogenitor cells to accumulate to form proper bones. Under normal physiological conditions EGFR/ERK-mediated IGFBP-3 is essential to suppress IGF-1R/mTOR in order to ensure efficient osteoblasts maturation.

Many possible interactions between IGF-1R and EGFR have been identified [20]. Cancer cells acquire resistance against EGFR inhibitor treatment via loss of IGFBP-3, which activates the IGF-1R signaling pathway [21, 22]. A tight regulation of IGFBP-3 signaling is not only essential for cancer treatment but also during bone development as shown by both Igfbp3 transgenic and knock-out mouse models. Long-bones of Igfbp3 transgenic mice overexpressing human IGFBP-3 demonstrate reduced trabecular and cortical bone density [23]. Igfbp3 $3^{-/-}$mice, on the other hand, develop a low-bone-mass phenotype comparable to Egfr-deficient mice comprising reduced trabecular bone volume and number with increased trabecular separation [24]. In agreement with our data, a link between EGFR and IGFBP-3 has also been described for primary human esophageal cells and esophageal squamous cell carcinomas indicating that EGFR indeed directly regulates IGFBP-3 [17].

The mTOR-pathway plays an important role during development by regulating cell survival, growth, differentiation and autophagy [25]. Recently, rapamycin-induced autophagy was shown to increase the number of osteoblasts and the mineralized area in fracture calluses of rats during bone fracture healing [26]. mTOR signaling has also been linked to other bone-related diseases like osteoarthritis (OA). Patients suffering from OA show increased mTOR protein and mRNA levels in affected joints [27]. Additionally, rapamycin treatment or deletion of mTOR in chondrocytes reduced the severity of experimental OA in mice [27, 28]. Reduced EGFR signaling, on the other hand, leads to a worse progression of experimental OA due to increased cartilage destruction in gefitinib-treated mice [29] and subchondral bone plate thickening with increased joint pain in genetically modified (Egfr ${ }^{\text {wa5/f }}$ Col2-Cre) animals [30]. These findings suggest that EGFR might not only negatively regulate the mTOR-pathway during bone development, but also during OA progression. Further 
studies are needed to investigate the impact of EGFR signaling on mTOR activation in bone-related diseases.

Mice with osteoblast-specific IGF-1R deletion display mineralization defects $[31,32]$. mTOR signaling pathway activation via IGF-1 has been reported to play a major role in bone development by regulating osteoblast differentiation in adult mice [32]. Moreover, osteoblast-specific deletion of $\mathrm{TSC} 2$, a negative regulator of the mTOR pathway, leads to elevated mTOR signaling with increased bone formation starting around 6 weeks after birth. Interestingly, three weeks after birth these mice showed an osteopenic-like phenotype with significantly increased trabecular separation, reduced bone volume to tissue volume and reduced number of trabecles [33]. As Egfr ${ }^{-1-}$ mice also exhibit an osteopenic bone phenotype with elevated mTOR expression in osteoblasts, we hypothesize that up-regulation of mTOR pathway might inhibit bone formation during embryonic and early postnatal development, whereas it induces bone mineralization in older animals. Consistently, treatment of pregnant dams with rapamycin largely rescued the low bone mass phenotype of $E g \mathrm{fr}^{-l-}$ embryos.

In summary, we demonstrate that impaired proliferation and enhanced differentiation of osteoblasts is responsible for the osteopenia and irregular mineralization in bones of $E g f r^{-I-}$ and $E g f r^{\Delta \mathrm{Ob}}$ mice. The bone defects of $E g \mathrm{fr}^{-1-}$ mice are not restricted to endochondral ossification, since mineralization defects are also apparent in skulls of $E g \mathrm{fr}^{-1-}$ pups. Therefore, defective osteoblast maturation very likely is the driving force for the mineralization defects in $\mathrm{Egfr}^{-/-}$mice. We identified the mTOR-pathway as a positive regulator of osteoblast differentiation, suppressed by EGFR/ERK/IGFBP-3-signaling and hyper-activated in its absence via IGF-1R. Future studies will address whether the cross-talk between these important signaling pathways is also operating in other tissues and under pathological conditions.

\section{Materials and methods}

\section{Mice}

$E g \mathrm{fr}^{-1-}$ mice have been described previously [4]. Egfr ${ }^{\mathrm{AOc}}$ mice were generated by breeding Egfrff mice [34] to LysMCre [35] transgenic mice. Egfr ${ }^{\Delta \mathrm{Ob}}$ mice were generated by crossing Egfr fff mice with Runx2-Cre [13] transgenic mice (kindly provided by Jan Tuckermann, University Ulm). Only male $E g f r^{\Delta \mathrm{Ob}}$ and littermate controls $\left(E g f r^{f f f}, E g f r^{f l+}\right.$ or Egfr $r^{f l+}$ Runx2-Cre) with a C57BL/6 genetic background were used for experiments. Genotyping was performed as previously described $[4,35,13]$. Mice were kept in the animal facility of the Medical University of Vienna in accordance with institutional policies and federal guidelines. All animal experiments conducted were compliant with federal laws and guidelines of the Medical University of Vienna.

\section{Whole mount stainings, histomorphometry, immunohistochemistry}

Mice were sacrificed at indicated time points. Whole mount stainings were performed as described previously [36]. For histological stainings, bones were fixed in 4\% PBS-buffered formaline and embedded either in paraffin or methylmetacrylate. $5 \mu \mathrm{m}$ paraffin sections were used for H.E.-stainings after decalcification in 0.5 M EDTA or uncalcified for VonKossa stainings (calvaria); methylmetacrylate was used for Von-Kossa stainings (long bone) and for Movat-stainings (osteoid). Histomorphometry was performed with Movat and/or H\&E-stainings according to the standardized protocols of the American Society for Bone and Mineral Research [37] on the Osteo-measure system (Osteometrix) in a blinded fashion. Immunohistochemistry was performed on $4 \mu \mathrm{m}$ formalin-fixed paraffin embedded and decalcified femur sections. Primary antibodies (for a full list see Table S1) were incubated overnight at $4{ }^{\circ} \mathrm{C}$ followed by HRP-based immunoreactivity detection (CST). Nonspecific binding was blocked by applying TBS-T containing 2\% BSA and 5\% normal goat serum. Quantifications of IHC stainings were performed in a blinded fashion by counting positive cells on the trabecular bone surface and results are shown as positive cells per bone perimeter.

\section{Primary osteoblast cultures}

Osteoblasts were cultured in $\alpha$-MEM containing ribonucleosides and deoxyribonucleosides (GlutaMAX, Sigma) and 10\% FBS (Autogen Bioclear). Primary osteoblasts were isolated from calvariae of neonatal mice (P1-P7) as previously described [38] and seeded at a density of 5.000 cells $/ \mathrm{cm}^{2}$. For differentiation, ascorbic acid $(50 \mu \mathrm{g} / \mathrm{ml})$ and $\beta$-glycerolphosphate $(10 \mathrm{mM})$ were added to the culture medium. Bone nodules were stained at differentiation day 21 using Alizarin Red (Sigma). For BrdU stainings, osteoblasts were cultured until $70 \%$ confluency and incubated with $10 \mu \mathrm{M}$ BrdU (Roche) for $4 \mathrm{~h}$, before fixation with $70 \%$ ethanol and staining with an anti-BrdU antibody according to the manufacturer's instructions (Becton Dickinson). Rapamycin (Wyeth), EGF (Roche) and IGF-1 (Promega) were used in concentrations indicated in the respective figure legends.

\section{Primary osteoclast cultures}

For osteoclast isolation, bone marrow cells were harvested from long-bones of 8 week old mice. Cells were cultured 
overnight in $\alpha$-MEM containing 10\% FBS. Non-adherent cells were harvested, counted and seeded in 6-well plates $\left(1.0 \times 10^{6}\right.$ cells $/$ well $)$ with M-CSF $(50 \mathrm{ng} / \mathrm{ml}) .48 \mathrm{~h}$ later RANKL $(50 \mathrm{ng} / \mathrm{ml})$ was added to induce differentiation for additional $96 \mathrm{~h}$.

\section{Total RNA isolation, Real-time qRT-PCR analysis}

Total RNA from osteoblasts and whole bone was isolated using peqGOLD TriFast reagent (Peqlab) or RNeasy Kit (Qiagen). cDNA synthesis was performed with ProtoScript II Reverse Transcriptase (NEB) according to the manufacturer's instructions. Real-time qRT-PCR was performed using the Power SYBR Green Master Mix (Thermo Fisher Scientific) together with the Applied Biosystems 7500 Fast Real-Time PCR System (Thermo Fisher Scientific) using the following primers: Collagen type 1 alpha 1 (Collal) 5'ACCTGGTCCACAAGGTTTCC-3' and 5'-GACCCATT GGACCTGAACCG-3'; Collagen type 1 alpha 2 (Colla2) 5'-GGTCCAAGAGGAGAACGTGG-3' and 5'-TGGGAC CTCGGCTTCCAATA-3'; Collagen type 2 alpha 1 (Col2al) 5'-GGCCAGGATGCCCGAAAATTA-3' and 5'CGCACCCTTTTCTCCCTTGT-3'; Collagen type 10 alpha 1 (Colloal) 5'-CATCTCCCAGCACCAGAATC-3' and 5'GCTAGCAAGTGGGCCCTTTA-3'; Epidermal growth factor receptor $(E g f r)$ 5'-TTGGAATCAATTTTACACCGAAT-3' and 5'-GTTCCCACACAGTGACACCA3'; Osteocalcin (Ocn) 5'-AGACTCCGGCGCTACCTT-3' and $5^{\prime}$-CTCGTCACAAGCAGGGTTAAG-3'; Osteonectin (On) $5^{\prime}$-TCTCAAAGTCTCGGGCCAAC-3' and 5'-ATGCAAATACATCGCCCCCT-3'; Osteopontin (Opn) 5'CTGGCTGAATTCTGAGGGACT- $3^{\prime}$ and $5^{\prime}$-TTCTGT GGCGCAAGGAGATT-3'; Osterix (Osx) 5'-TGCCTGAC TCCTTGGGACC-3' and 5'-TAGTGAGCTTCTTCCTCA AGCA-3'; Runt-related transcription factor 2 (Runx2) 5'-GCCGGGAATGATGAGAACTA-3' and 5'-GGACCGT CCACTGTCACTTT-3'; Expression levels were standardized to the primer set specific for TATA-binding protein (Tbp): 5'-GGGGAGCTGTGATGTGAAGT-3' and 5'CCAGGAAATAATTCTGGCTCAT-3'.

\section{Western blot analysis}

Western blot analysis was performed as previously described [39]. For a full list of the antibodies used, please see Table S1.

\section{Enzyme-linked immunosorbent assay (ELISA)}

Mouse IGF-1 (Quantikine, R\&D Systems) and IGF-2 (RayBiotech) Immunoassays were performed according to manufacturer's instructions with $48 \mathrm{~h}$-old supernatants collected from osteoblast cultures on differentiation day 14 . Osteocalcin (Alfa Aesar) and CTX-1 Elisa (RatLaps, IDS Immunodiagnostic Systems) were performed according to the manufacturer's instructions with serum isolated from male mice at p21 and p210. Mouse IGFBP-3 Elisa (R\&D Systems) was performed with $48 \mathrm{~h}$-old supernatants collected from osteoblast cultures on differentiation day 21 or from undifferentiated osteoblast precursors. Serum IGFBP-3 levels where analyzed in serum isolated from $\mathrm{p} 7$ and p210 mice. For IGFBP-3 quantification in whole tibia protein lysates from $\mathrm{p} 7$ mice, $20 \mu \mathrm{g}$ protein/well were applied after Bradford-based protein measurement (Bio-Rad).

\section{Rapamycin treatment}

Rapamycin (Sigma) was diluted in injection vehicle containing 10\% PEG-400 and 17\% Tween- 80 in $1 \times$ PBS. Mice were randomly assigned into two groups and injected every $12 \mathrm{~h}$ between E15.5 and E16.5 either with $5 \mathrm{mg}$ Rapamycin per $\mathrm{kg}$ bw in $200 \mu \mathrm{l}$ injection vehicle or with $200 \mu \mathrm{l}$ injection vehicle alone according to a published protocol [18].The investigators were not blinded during the experiment.

\section{Statistical methods}

Sample size calculation: For in vivo treatment experiments a minimum of six embryos per group were considered, which ensures a $90 \%$ power to detect a difference in means of 2 standard deviations at the significance level of 0.05 . Based on the central limit theorem, we can assume a normal distribution of mean values even if the underlying variable is not perfectly normally distributed. Unless otherwise stated experiments were performed at least 2 times and data are shown as mean \pm s.e.m. For analyses of IHC and qRT-PCR data, univariable comparisons of expression values between groups were analyzed by unpaired two-tailed Student's $t$-test with $f$-test to ensure comparable variances between the groups. For analysis of hypertrophic chondrocyte zone, BV/ TV and qRT-PCR analysis after Rapamycin treatment, oneway ANOVA was applied. A $p$-value below 0.05 was considered statistically significant and was marked with a star $(*), p<0.01$ with 2 stars $(* *), p<0.001$ with 3 stars $(* * *)$ and $p<0.0001$ with 4 stars $(* * * *)$. For analyses, SAS for Windows 9.1.3 (The SAS Institute, Inc., Cary, North Carolina, USA) and Prism 6 (GraphPad) were used.

Acknowledgements We thank Mruniya Vaibhavkumar Gawali, Theresia Lengheimer and Martina Hammer for maintaining mouse colonies, Sarah Bardakji and Malgorzata Tryniecki for genotyping, Temenuschka Baykuscheva-Gentscheva for technical assistance and Alexander Kainz for helping with statistical analysis. The authors also 
thank Reinhold Erben for helpful discussions. This work was supported by the Austrian Science Fund (FWF) (DK W1212), the FWF-grant I764-B13, the Deutsche Forschungsgemeinschaft (CRC 1149, Priority Program Immunobone Tu220/6 to J.T.) and "Fonds der Stadt Wien für innovative interdisziplinäre Krebsforschung" (AP00288OFF). M.S. is supported by an ERC-Advanced grant (ERC-2015-AdG TNT-Tumors 694883).

\section{Compliance with ethical standards}

Conflict of interest The authors declare that they have no conflict of interest.

Open Access This article is licensed under a Creative Commons Attribution 4.0 International License, which permits use, sharing, adaptation, distribution and reproduction in any medium or format, as long as you give appropriate credit to the original author(s) and the source, provide a link to the Creative Commons license, and indicate if changes were made. The images or other third party material in this article are included in the article's Creative Commons license, unless indicated otherwise in a credit line to the material. If material is not included in the article's Creative Commons license and your intended use is not permitted by statutory regulation or exceeds the permitted use, you will need to obtain permission directly from the copyright holder. To view a copy of this license, visit http://creativecommons. org/licenses/by/4.0/.

\section{References}

1. Wagner EF, Karsenty G. Genetic control of skeletal development. Curr Opin Genet Dev. 2001;11:527-32.

2. Cohen MM Jr.. The new bone biology: pathologic, molecular, and clinical correlates. Am J Med Genet A. 2006;140:2646-706.

3. Sibilia M, Kroismayr R, Lichtenberger BM, Natarajan A, Hecking M, Holcmann M. The epidermal growth factor receptor: from development to tumorigenesis. Differentiation. 2007;75:770-87.

4. Sibilia M, Wagner EF. Strain-dependent epithelial defects in mice lacking the EGF receptor. Science. 1995;269:234-38.

5. Threadgill DW, Dlugosz AA, Hansen LA, Tennenbaum T, Lichti $\mathrm{U}$, Yee D, et al. Targeted disruption of mouse EGF receptor: effect of genetic background on mutant phenotype. Science. 1995;269:230-34.

6. Sibilia M, Wagner B, Hoebertz A, Elliott C, Marino S, Jochum W, et al. Mice humanised for the EGF receptor display hypomorphic phenotypes in skin, bone and heart. Development. 2003;130:4515-25.

7. Wang K, Yamamoto H, Chin JR, Werb Z, Vu TH. Epidermal growth factor receptor-deficient mice have delayed primary endochondral ossification because of defective osteoclast recruitment. J Biol Chem. 2004;279:53848-56.

8. Zhang X, Tamasi J, Lu X, Zhu J, Chen H, Tian X, et al. Epidermal growth factor receptor plays an anabolic role in bone metabolism in vivo. J Bone Mineral Res. 2011;26:1022-34.

9. Hall KC, Hill D, Otero M, Plumb DA, Froemel D, Dragomir CL, et al. ADAM17 controls endochondral ossification by regulating terminal differentiation of chondrocytes. Mol Cell Biol. 2013;33:3077-90.

10. Chandra A, Lan S, Zhu J, Siclari VA, Qin L. Epidermal growth factor receptor (EGFR) signaling promotes proliferation and survival in osteoprogenitors by increasing early growth response 2 (EGR2) expression. J Biol Chem. 2013;288:20488-98.

11. Karsenty G, Wagner EF. Reaching a genetic and molecular understanding of skeletal development. Dev Cell. 2002;2:389-406.
12. Yarden Y. The EGFR family and its ligands in human cancer. signalling mechanisms and therapeutic opportunities. Eur J Cancer. 2001;37:S3-8.

13. Rauch A, Seitz S, Baschant U, Schilling AF, Illing A, Stride B, et al. Glucocorticoids suppress bone formation by attenuating osteoblast differentiation via the monomeric glucocorticoid receptor. Cell Metab. 2010;11:517-31.

14. Guntur AR, Rosen CJ. IGF-1 regulation of key signaling pathways in bone. Bone Rep. 2013;2:437.

15. Mohseni-Zadeh S, Binoux M. Insulin-like growth factor (IGF) binding protein-3 interacts with the type 1 IGF receptor, reducing the affinity of the receptor for its ligand: an alternative mechanism in the regulation of IGF action. Endocrinology. 1997; 138:5645-48.

16. Ricort JM, Binoux M. Insulin-like growth factor (IGF) binding protein-3 inhibits type 1 IGF receptor activation independently of its IGF binding affinity. Endocrinology. 2001;142:108-13.

17. Takaoka M, Harada $\mathrm{H}$, Andl $\mathrm{CD}$, Oyama $\mathrm{K}$, Naomoto $\mathrm{Y}$, Dempsey KL, et al. Epidermal growth factor receptor regulates aberrant expression of insulin-like growth factor-binding protein 3. Cancer Res. 2004;64:7711-23.

18. Liu KJ, Arron JR, Stankunas K, Crabtree GR, Longaker MT. Chemical rescue of cleft palate and midline defects in conditional GSK-3beta mice. Nature. 2007;446:79-82.

19. Zhu J, Shimizu E, Zhang X, Partridge NC, Qin L. EGFR signaling suppresses osteoblast differentiation and inhibits expression of master osteoblastic transcription factors Runx2 and Osterix. J Cell Biochem. 2011;112:1749-60.

20. Jones HE, Gee JM, Hutcheson IR, Knowlden JM, Barrow D, Nicholson RI. Growth factor receptor interplay and resistance in cancer. Endocr Relat Cancer. 2006;13:S45-51.

21. Chakravarti A, Loeffler JS, Dyson NJ. Insulin-like growth factor receptor I mediates resistance to anti-epidermal growth factor receptor therapy in primary human glioblastoma cells through continued activation of phosphoinositide 3-kinase signaling. Cancer Res. 2002;62:200-7.

22. Guix M, Faber AC, Wang SE, Olivares MG, Song Y, Qu S, et al. Acquired resistance to EGFR tyrosine kinase inhibitors in cancer cells is mediated by loss of IGF-binding proteins. J Clin Invest. 2008;118:2609-19.

23. Silha JV, Mishra S, Rosen CJ, Beamer WG, Turner RT, Powell $\mathrm{DR}$, et al. Perturbations in bone formation and resorption in insulin-like growth factor binding protein-3 transgenic mice. J Bone Miner Res. 2003;18:1834-41.

24. Yakar S, Rosen CJ, Bouxsein ML, Sun H, Mejia W, Kawashima $\mathrm{Y}$, et al. Serum complexes of insulin-like growth factor-1 modulate skeletal integrity and carbohydrate metabolism. FASEB J. 2009;23:709-19.

25. Kim YC, Guan KL. mTOR: a pharmacologic target for autophagy regulation. J Clin Invest. 2015;125:25-32.

26. Yang GE, Duan $\mathrm{X}$, Lin $\mathrm{D}$, Li T, Luo D, Wang L, et al. Rapamycin-induced autophagy activity promotes bone fracture healing in rats. Exp Ther Med. 2015;10:1327-33.

27. Zhang Y, Vasheghani F, Li YH, Blati M, Simeone K, Fahmi H, et al. Cartilage-specific deletion of mTOR upregulates autophagy and protects mice from osteoarthritis. Ann Rheum Dis. 2015;74:1432-40.

28. Carames B, Hasegawa A, Taniguchi N, Miyaki S, Blanco FJ, Lotz M. Autophagy activation by rapamycin reduces severity of experimental osteoarthritis. Ann Rheum Dis. 2012;71:575-81.

29. Zhang X, Zhu J, Liu F, Li Y, Chandra A, Levin LS, et al. Reduced EGFR signaling enhances cartilage destruction in a mouse osteoarthritis model. Bone Res. 2014;2:14015.

30. Jia H, Ma X, Tong W, Doyran B, Sun Z, Wang L, et al. EGFR signaling is critical for maintaining the superficial layer of 
articular cartilage and preventing osteoarthritis initiation. Proc Natl Acad Sci USA. 2016;113:14360-65.

31. Zhang M, Xuan S, Bouxsein ML, von Stechow D, Akeno N, Faugere MC, et al. Osteoblast-specific knockout of the insulin-like growth factor (IGF) receptor gene reveals an essential role of IGF signaling in bone matrix mineralization. J Biol Chem. 2002;277: 44005-12.

32. Xian L, Wu X, Pang L, Lou M, Rosen CJ, Qiu T, et al. Matrix IGF-1 maintains bone mass by activation of mTOR in mesenchymal stem cells. Nat Med. 2012;18:1095-1.

33. Riddle RC, Frey JL, Tomlinson RE, Ferron M, Li Y, Digirolamo DJ, et al. Tsc2 is a molecular checkpoint controlling osteoblast development and glucose homeostasis. Mol Cell Biol. 2014; 34:1850-62.

34. Lanaya H, Natarajan A, Komposch K, Li L, Amberg N, Chen L, et al. EGFR has a tumour-promoting role in liver macrophages during hepatocellular carcinoma formation. Nat Cell Biol. 2014;16:972-81. 971-977
35. Clausen BE, Burkhardt C, Reith W, Renkawitz R, Forster I. Conditional gene targeting in macrophages and granulocytes using LysMcre mice. Transgenic Res. 1999;8:265-77.

36. Wallin J, Wilting J, Koseki H, Fritsch R, Christ B, Balling R. The role of Pax-1 in axial skeleton development. Development. 1994;120:1109-21.

37. Parfitt AM, Drezner MK, Glorieux FH, Kanis JA, Malluche H, Meunier PJ, et al. Bone histomorphometry: standardization of nomenclature, symbols, and units. Report of the ASBMR Histomorphometry Nomenclature Committee. J Bone Miner Res. 1987;2:595-10.

38. Jochum W, David JP, Elliott C, Wutz A, Plenk H Jr., Matsuo K, et al. Increased bone formation and osteosclerosis in mice overexpressing the transcription factor Fra-1. Nat Med. 2000;6:980-84.

39. Sibilia M, Fleischmann A, Behrens A, Stingl L, Carroll J, Watt FM, et al. The EGF receptor provides an essential survival signal for SOS-dependent skin tumor development. Cell. 2000;102:211-20. 